\title{
MECHANICAL PROPERTIES OF TITANIUM PROCESSED BY ECAP
}

\author{
${ }^{1}$ Oskar KWARTENG, ${ }^{2}$ Miroslav GREGER, ${ }^{3}$ Wojciech MAZIARZ \\ 'VÍTKOVICE HAMMERING, a. s., Ostrava-Vitkovice, Czech Republic, EU, kwarteng@vitkovice.com \\ ${ }^{2}$ VSB -Technical University of Ostrava, Ostrava, Czech Republic, EU, miroslav.greger@vsb.cz \\ ${ }^{3}$ Polish Academy of Sciences, IMMS, Krakow, EU, Poland, w.maziar@imim.pl
}

\section{https://doi.org/10.37904/metal.2021.4119}

\begin{abstract}
Mechanical properties and the deformation behavior of the equal channel angular pressing processed material were investigated by the tensile tests using miniaturized specimens, hardness and by so called penetration tests. The significant increase in yield stress and hardness after equal channel angular pressing was discussed by two strengthening mechanisms. Based on these mechanisms, variations of the yield stress and hardness as a function of the pass numbers were related to the calculated dislocation densities and the average boundary spacing. Also it was suggested that the absorption of the dislocations into grain boundaries would be an effective recovery process for the absence of the strain hardening.
\end{abstract}

Keywords: Titanium, ECAP, microstructure, mechanical properties

\section{INTRODUCTION}

During the equal channel angular pressing (ECAP) a metal billet is pressed through a die consisting of two channels, equal in cross section and intersesting at an angle (Figure 1). The billet undergoes essentially simple shear deformation but retains the same cross-sectional geometry, so that it is possible to repeat the pressings for a number of passes, each one refining the grain till the extent which is determined by the material characteristics.

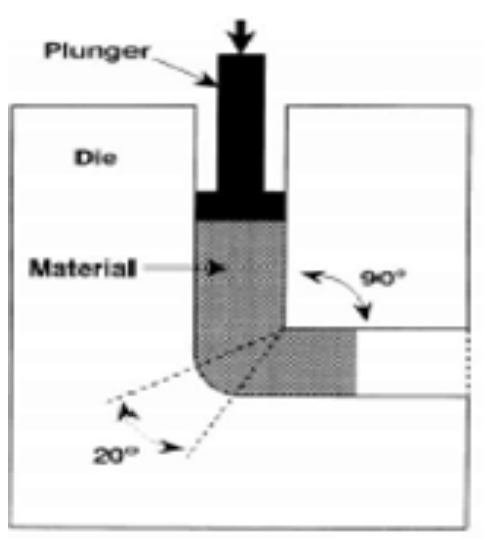

Figure 1 Schematic illustration of a die variantion present used in the of investigation, with $\varphi 90$ and

$$
\psi=20^{\circ}
$$

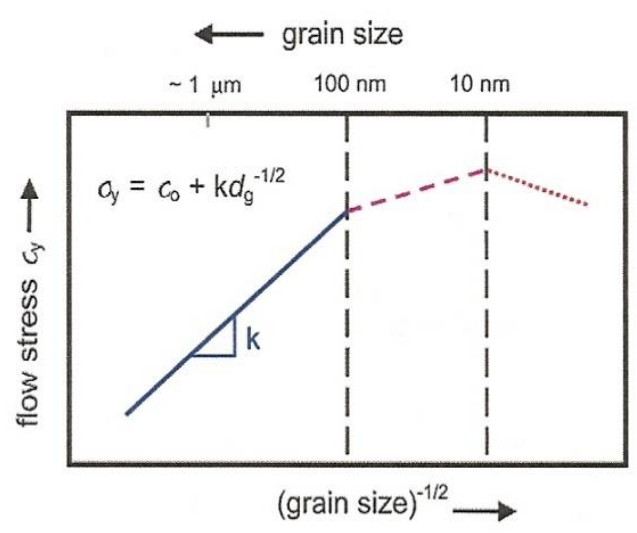

Figure 2 Schematic representation of the yield stress as funkction of grain size in $\mathrm{nc}$ metals and alloys [6]

Extrusion by ECAP method enables obtaining of a fine-grain structure in larger volumes. Products made by this technique are characterised by high strength properties (Figure 2), and they can be potentially used at subsequent super-plastic forming [1-3]. Magnitude of deformation, development of structure and resulting mechanical properties achieved by this technique depend notably on: homologous temperature $T_{h}$, size of 
grain $d_{z}$, deformation speed $\varepsilon^{\circ}$, homologous tension in die $(\sigma / E)$, density of structural failures, on purity, etc [4-6]. Obtaining of the required final structure depends primarily on geometry of todie, obtained magnitude and speed of deformation and temperature.

\section{STRUCTURE AND PROPERTIES OF COMMERCIAL PURE TITANIUM}

Microstructure of deformed specimens after testing is shown in Figures 3- 4. Specimens were sectioned along the gauge and grip parts of the deformed sample. The samples were then polished etched using $10 \% \mathrm{HF}$, $10 \% \mathrm{HNO}_{3}$ and $80 \% \mathrm{H}_{2} \mathrm{O}$ for 20 second.

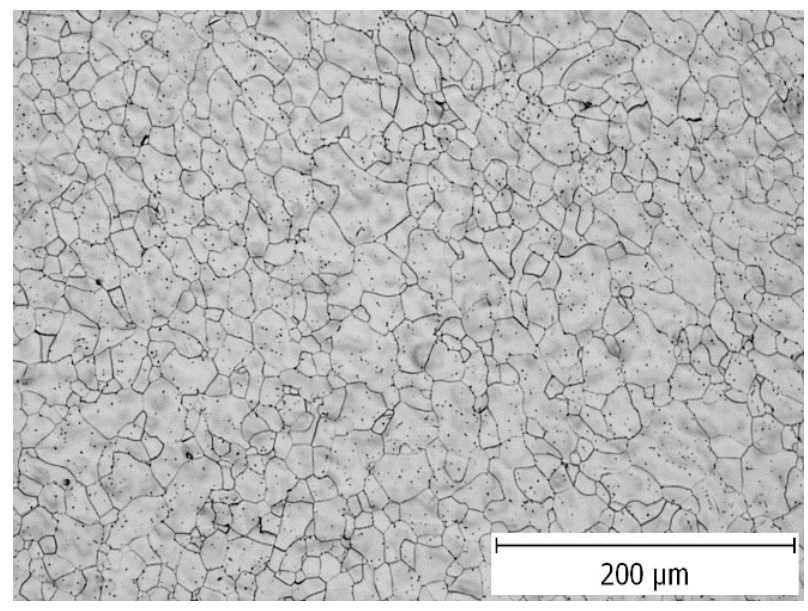

Figure 3 Initial microstructure titanium $\mathrm{ECAP}+650^{\circ} \mathrm{C} / 1 \mathrm{~h}$.

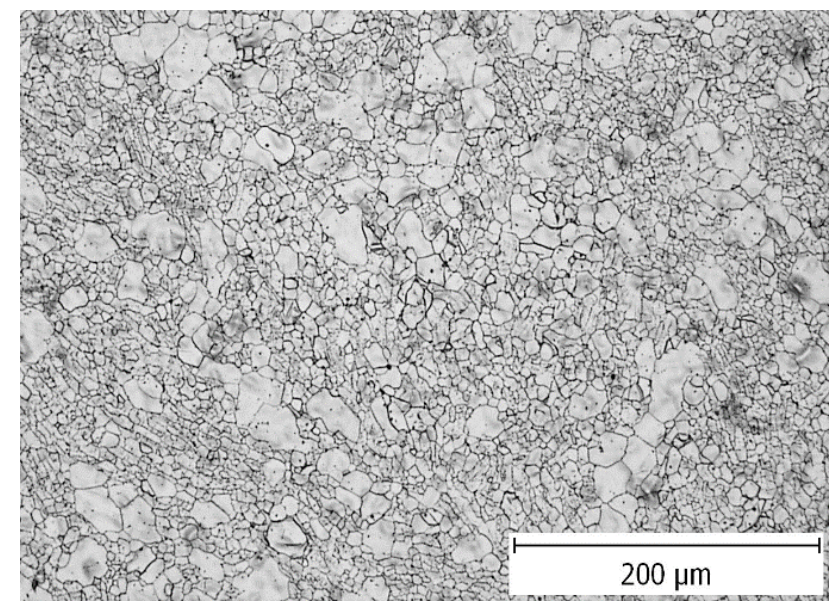

Figure 4 Microstructure titanium after 2 passes

Chemical analysis and mechanical properties commercially pure (CP) titanium are given in the Tables 1-2.

Table 1 Chemical analysis titanium Grade 2, (weight \%)

\begin{tabular}{|c|c|c|c|c|c|c|}
\hline $\mathbf{N}$ & $\mathbf{0}$ & $\mathbf{C}$ & $\mathbf{F e}$ & $\mathbf{A l}$ & $\mathbf{C r}$ & $\mathbf{T i}$ \\
\hline 0.004 & 0.068 & 0.008 & 0.03 & 0.01 & 0.01 & Rest. \\
\hline
\end{tabular}

Table 2 Tensile properties of titanium Grade 2 after annealing $649^{\circ} \mathrm{C} / 1$ hour (ASTM E8)

\begin{tabular}{|c|c|c|c|}
\hline $\begin{array}{c}\mathbf{R}_{\mathbf{m}} \\
(\mathbf{M P a})\end{array}$ & $\begin{array}{c}\mathbf{R}_{\mathbf{p 0}, 2} \\
(\mathbf{M P a})\end{array}$ & $\begin{array}{c}\mathbf{A} \\
(\%)\end{array}$ & $\begin{array}{c}\mathbf{Z} \\
(\%)\end{array}$ \\
\hline 375 & 230 & 51 & 71 \\
\hline
\end{tabular}

\section{THE TECHNOLOGY FOR MANUFACTURE OF ULTRA-FINE GRAIN TITANIUM}

The main objective of experiments was manufacture of ultra-fine grain Titanium, description and optimisation of its properties from the viewpoint of their resistance to corrosion, strength and other mechanical properties from the viewpoint of its application in dental implants. Chemical purity of semi products for titanium was ensured by technology of melting in vacuum and by zonal remelting. The obtained semi-product was under defined parameters of forming processed by the equal channel angular pressing technology. The output was ultra-fine grain titanium with strength about $960 \mathrm{MPa}$. Table 3 summarises the obtained basic mechanical properties ultra-fine grain titanium after ECAP. The obtained ultra-fine grain titanium will be further processed by technology (of rotation forging) and drawing to the shape suitable for dental implants. 
Table 3 Mechanical properties ( $n$ )Ti after ECAP

\begin{tabular}{|c|c|c|c|c|}
\hline Forming processed & $\begin{array}{c}\text { Tensile stress } \\
(\mathbf{M P a})\end{array}$ & $\begin{array}{c}\text { Elongation at break } \\
(\%)\end{array}$ & $\begin{array}{c}\text { Young's modulus } \\
(\mathbf{G P a})\end{array}$ & $\begin{array}{c}\mathbf{d}_{\mathbf{z}} \\
\text { (nm) }\end{array}$ \\
\hline ECAP & 960 & 12 & 100 & 100 to 300 \\
\hline
\end{tabular}

\section{RESULTS}

Samples from individual heats were processed by the ECAP. The samples for mechanical tests and for microstructural analyses were prepared from individual variants of processing. On the basis of the results of standard tensile tests (Figure 5), particularly the obtained strength values, several variants were chosen for more detailed investigation of developments occurring in the structure at application of the ECAP and subsequent drawing after heat treatment.

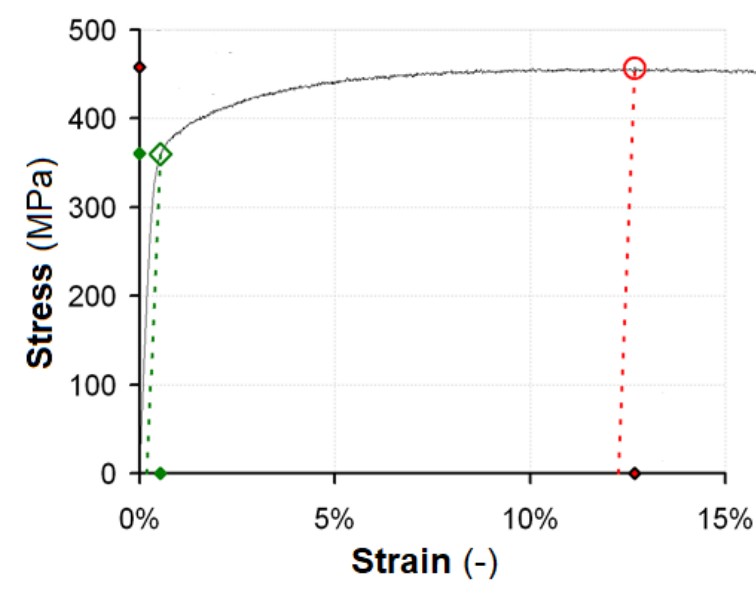

a)

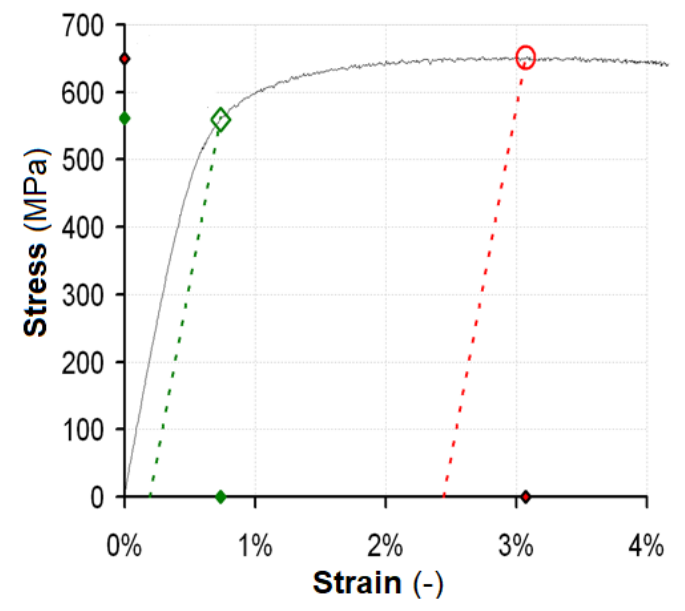

b)

Figure 5 Stress - strain curve commercially pure titanium: a) initial sample, b) after 6 passes

The structure was analysed apart from light microscopy also by the TEM. Structure of ultra-fine grain titanium after application of the ECAP process is shown in the Figures 6 - 7 .

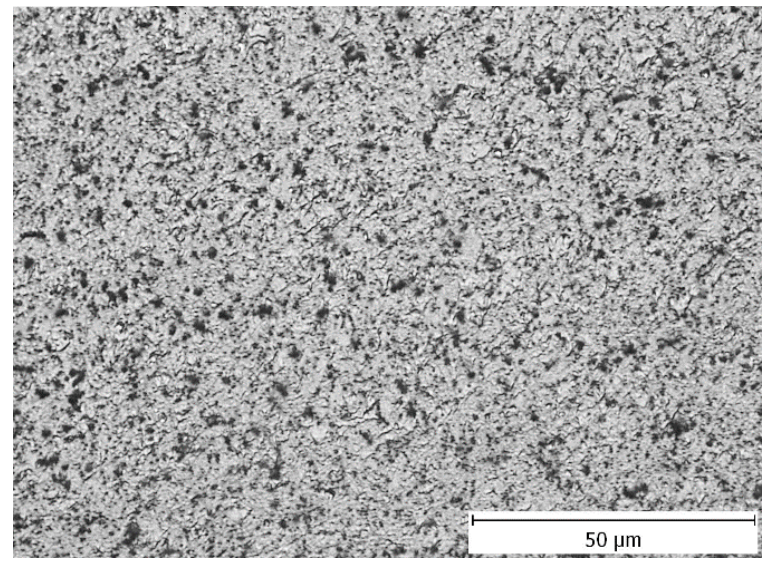

Figure 6 Microstructure of ultra-fine grain titanium after ECAP (6 passes)

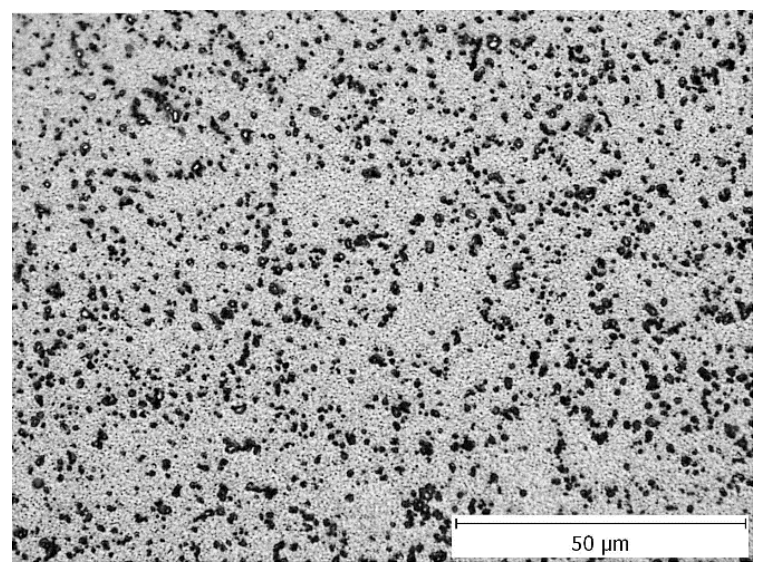

Figure 7 Microstructure of ultra-fine grain titanium after ECAP (10 passes)

In the Figures 8 is also presented correlations for steels (dashed line) and titanium [7]. From both figures is clearly seen, that origin correlation for steel can not be used for evaluation of mechanical properties of titanium by punch test, new developed correlation changed significantly probably due to friction coefficient effect or 
lattice effect. Work is still continuing to evaluate reason of the ECAP passeshis effect as well as to get a more results for titanium and Ti alloys. When the grain size is reduced to $0.1 \mu \mathrm{m}$ or less an in the case of titanium after 8 passes ECAP.

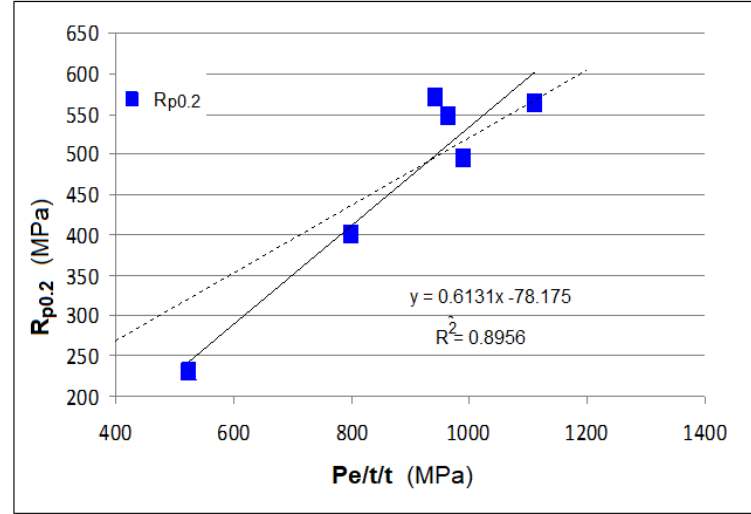

a)

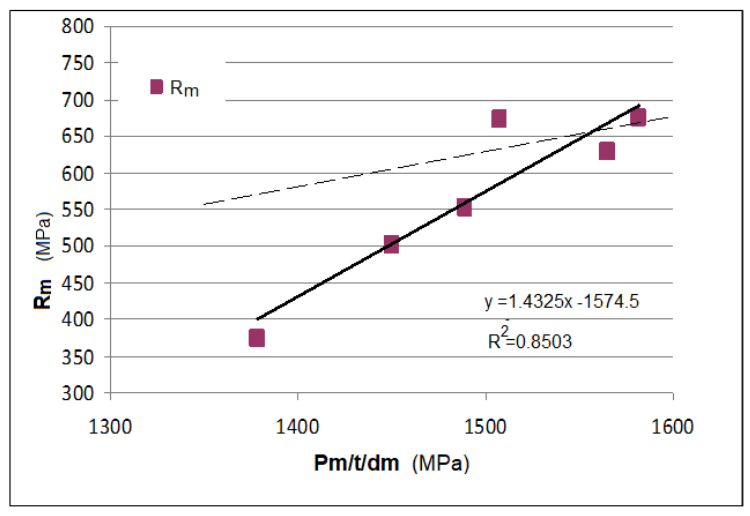

b)

Figure 8 Correlation for steel and titanium yield stress (a) and tensile stress (b)

The resulting fracture surface from a tensile specimen still continues to show what appears to be dimpled rupture with the important difference that the dimple diameter on an average is finer in size relative to those seen in Figures 9, 10.

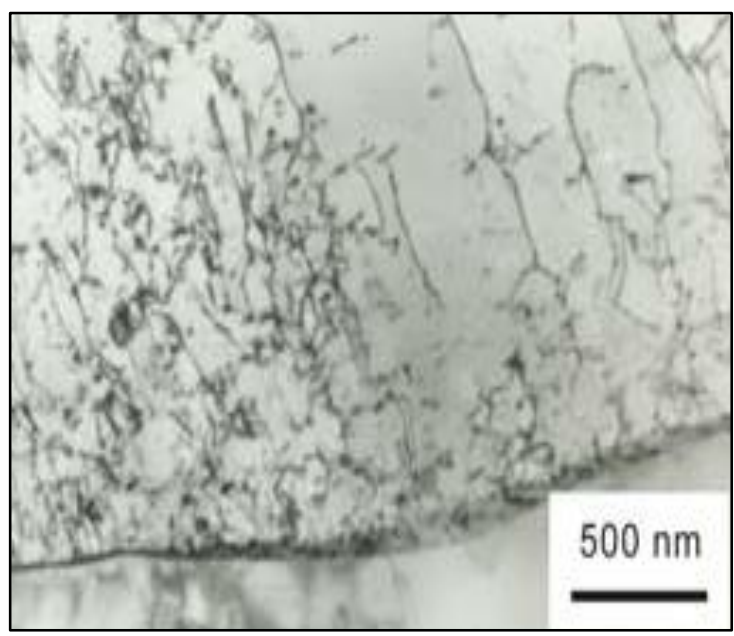

Figure 9 Substructure of titanium Grade 2 in the sample initial state

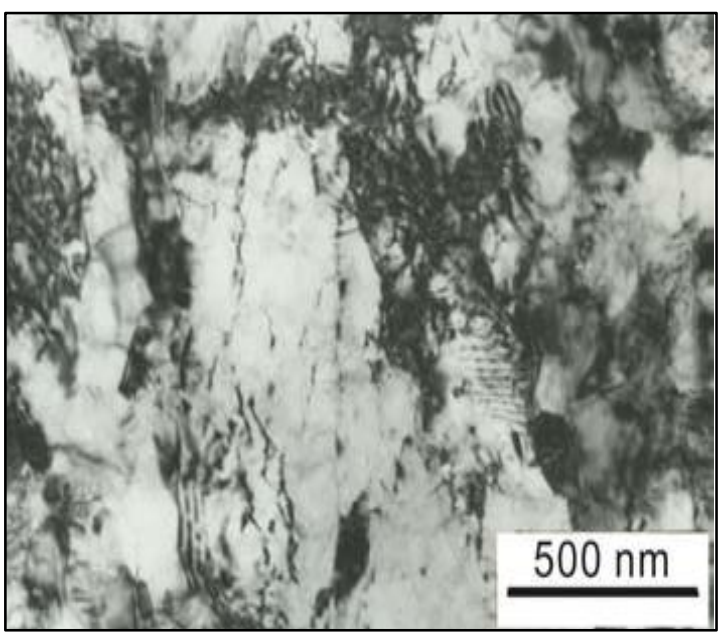

Figure 10 Substructure of titanium grade 2 in the after 10 ECAP passes

\section{CONCLUSIONS}

Technology of manufacture of ultra-fine grain titanium was proposed and experimentally verified. Grain refinement in input materials was obtained using the equal channel angular pressing process. In conformity with the Hall-Petch, relation the strength properties of commercially pure titanium increased significantly as a result of grain refinement. The obtained mechanical properties correspond with the declared requirements. Ultra-fine grain has higher specific strength properties than ordinary titanium. To evaluate mechanical properties of Ti standards tensile tests were carried out as well as very potential method (small punch test) were used. New correlation has been found for titanium that differs significantly from correlation using for steels. Further work is necessary to get more data for new developed correlation on titanium and Ti alloys. Based on the experimental results can be seen that small punch tests can be using to evaluate for titanium especially in the case, when small amount of experimental materials is expected. 


\section{ACKNOWLEDGEMENTS}

The authors are grateful to the Czech Ministry of Education, project MOBILITY, No. 8JPL19035

\section{REFERENCES}

[1] DANAIL, G., NIKOLAY, F., STOYAN, D. Classification, properties and application of titanium and its alloys. Proceedings of University of Ruse. 2016, vol. 55, book 2, pp. 27-32.

[2] WANG, M., WANG, Y, HUANG, A., GAO, L. Promising tensile and fatigue properties of commercially pure titanium processed by rotary swaging and annealing treatment. Materials. 2018, vol. 11, no. 11, pp. $2261-2267$.

[3] HUSAAIN, Z., AHMED, A., IRFAN, O.M., AL-MUFADI, F. Severe plastic deformation and its application on processing titanium: A Review. Int. J. Eng. Technol. 2017, vol. 9, no. 6, pp. 626-632.

[4] SANOSH, K. P., BALAKRISHNAN, A., FRANCIS, L. et al. Vickers and Knoop micro-hardness behavior of coarseand ultra-fine grained titanium. J. Mater. Sci. Technol. 2010, vol. 26, no.10, pp. 904-907.

[5] MERTOVÁ, K., PALÁN, J. DUCHEK, M. STUDECKÝ, T. et al. Continuous production of pure titanium with ultrafine to nanocrystalline microstructure. Materials. 2020, vol. 13, pp. 336-341.

[6] SALIHUA, S. A., SULEIMANB, Y. I., EYINAVIA, A. I. Classification, properties and applications of titanium and its alloys used in automotive industry. American Journal of Engineering Research. 2019, vol. 8, no. 8, pp. 92-98.

[7] GREGER, M., WIDOMSKÁ, M., KANDER, L. Mechanical properties of ultra-fine grain titanium. Journal of Achievements in Materials and Manufacturing Engineering. 2010, vol. 40, iss.1, pp. 33-40. 